\title{
C. EL DERECHO DE AMPARO
}

JUAN M. PELLERANO GÓMEZ 



\title{
C. EL DERECHO DE AMPARO
}

POR

\author{
JUAN M. PELLERANO GÓMEZ
}

1. Hoy conserva toda su fuerza la sentencia formulada por NORBERTO BOBBIO en el año de 1964, de que «el problema grave de nuestro tiempo respecto de los derechos humanos no es el de fundamentarlos, sino el de protegerlos" ', por lo que es de importancia capital el distinguir cuáles son los medios procesales que garantizan el ejercicio efectivo de los derechos fundamentales de toda persona, al igual a como acontece de ordinario con la protección que se brinda cuando se cometen transgresiones a las normas del Derecho privado, lo que adquiere matices dramáticos en paises como la República Dominicana, que, dominada en el decurso de su historia por un estatismo presidencialista que tiene sus raíces en el sistema colonial, no satisface aún las condiciones sociológicas, políticas y jurisdiccionales que hagan realidad la vigencia de esos derechos. Sin embargo, es de interés determinar cuáles son los medios procesales que permiten a los dominicanos reclamar el respeto a sus derechos fundamentales, para lo cual es necesario recurrir al auxilio del Derecho constitucional comparado a causa de las deficiencias del sistema jurídico.

En América Latina suele llamarse derecho, acción o recurso de amparo a los medios procesales destinados a garantizar judicialmente los derechos de la persona. A seguidas esbozaré, en el ámbito del Derecho dominicano (I), el derecho de amparo y la acción de amparo, para a seguidas (II) determinar las condiciones de admisibilidad de la acción de amparo y concluir (III) precisando los principios que la rigen.

1 Citado por Sommermann, K. P., "La Filosofía, el Derecho y la Teoría de los Derechos Fundamentales en España", publicado en el volumen Pasado y Presente de los Derechos Humanos, Madrid 1990, p. 102. 


\section{EL DERECHO DE AMPARO Y LA ACCIÓN DE AMPARO}

2. El libre acceso a la justicia. El amparo judicial. Los derechos y libertades que la Constitución reconoce a toda persona son declaraciones y reconocimientos sin la fuerza que permita sostenerlos.

La instauración del Poder Judicial en parte de la organización del Estado, con la misión específica de dirimir los conflictos que surjan en el seno de la sociedad, sean quienes sean sus partes o actores, presupone para toda persona el libre acceso a los tribunales de justicia para la solución de cualquier transgresión a los derechos de que es titular, lo que es tanto un medio para dar fuerza a los derechos y garantías que le reconoce la Constitución como una vía destinada a garantizar su seguridad, tanto en lo que se refiere a su integridad física y a la de sus bienes como en lo que respecta a su libertad.

Cuando el artículo 8 de la Constitución proclama que el fin principal del Estado es la protección efectiva de los derechos de la persona, es evidente que la pone a cargo del Poder Judicial al que instituye en guardián de todos los derechos y garantías de que es titular, por lo que la jurisprudencia ha podido afirmar que "la Suprema Corte de Justicia debe desempeñar siempre y a cabalidad su papel de guardiana de la Constitución de la República y del respeto a los derechos individuales y sociales consagrados en ella" ${ }^{2}$.

El derecho de libre acceso a la justicia también se fundamenta en el principio de igualdad que consagra el artículo 100 de la Constitución e implica una igualdad de trato por el juez en la aplicación de las mismas leyes. Ese libre acceso a la justicia tiene un ámbito general y versa sobre todos los derechos de que es titular la persona, cual que fuera su naturaleza, ya se trate de los llamados fundamentales o de simples prerrogativas de índole patrimonial o extrapatrimonial, del cual existe consagración expresa en el artículo 14 del Pacto Internacional de Derechos Civiles y Políticos, que es norma de derecho interno dominicano, de la manera siguiente:

"14.1. Todas las personas son iguales ante los tribunales y cortes de justicia. Toda persona tendrá derecho a ser oída públicamente y con las debidas garantías por un tribunal competente, independiente e impar-

1 Sentencia de 5 de octubre de 1990. 
cial, establecido por la ley, en la sustanciación de cualquier acusación de carácter penal formulada contra ella o para la determinación de sus derechos y obligaciones de carácter civil."

Cuando el derecho de libre acceso a la justicia versa sobre la protección de los derechos fundamentales es, en puridad, la puesta en obra de un derecho de amparo ante la autoridad judicial para la solución de todas las violaciones a los derechos humanos de que ha sido víctima, las cuales pueden provenir tanto de funcionarios o agentes de la autoridad pública como de simples particulares.

Ese derecho de amparo permite tener acceso a los tribunales del orden judicial y a los del orden administrativo mediante los procedimientos que tienden a asegurar, de manera general, el respeto a la regla de derecho ${ }^{3}$, es el amparo judicial.

3. Fundamento constitucional del derecho de amparo. El amparo constitucional. La Reforma proclamada el 26 de noviembre de 1966 es el texto de la Constitución de los dominicanos. En él no se hace mención ni referencia alguna al derecho de amparo ni a la acción de amparo, no obstante a que dedica toda una sección a enunciar "Los Derechos Individuales y Sociales".

Tiene particular interés su artículo 10, que expresa:

"La enumeración contenida en los artículos 8 (de los Derechos Individuales y Sociales) y 9 (De los Deberes) no es limitativa, y por consiguiente no excluye otros derechos y deberes de igual naturaleza."

El que el párrafo capital del artículo 8 de la Constitución exprese "se reconoce como finalidad principal del Estado la protección efectiva de los derechos de la persona humana y el mantenimiento de los medios que le permitan perfeccionarse progresivamente dentro de un orden de libertad individual y de justicia social compatible con el orden público y los derechos de todos", y que la enumeración que subsigue sea la de los llamados derechos fundamentales, obliga a admitir, independientemente de cualquier otra consideración, que los "otros derechos" a que se refiere ese artículo 10 , son los que comúnmente se denominan derechos

3 I. Pellerano Gómez, J. M., "La Constitución y el Hombre», Listín Diario, 11 de febrero, 25 febrero y 25 marzo de 1987. 
humanos, los cuales constituyen el derecho natural de la persona y de la sociedad y que son la resultante de los fines que les corresponde alcanzar, por lo que esos otros derechos de la persona están implícitamente enumerados, con el mismo carácter de derechos fundamentales, al igual que las garantías procesales que hacen efectiva su existencia y ejercicio.

Cuando se trata de enumerar cuáles son esos "otros derechos", es necesario acudir, entre otros medios, a las enunciaciones contenidas en las convenciones internacionales de que es signataria la República y que son normas de derecho interno por haber sido adoptadas por los poderes públicos.

Ellas son la Declaración Universal de los Derechos del Hombre formulada por la Asamblea de la Organización de las Naciones Unidas del 10 de diciembre de 1948, el Pacto Internacional de Derechos Civiles y Políticos del 16 de diciembre de 1966, aprobado por Resolución del Congreso Nacional, del 8 de noviembre de 1977, y la Convención Americana de los Derechos Humanos del 22 de noviembre de 1969, aprobada por Resolución del 25 de diciembre de 1977. Esas convenciones crean parámetros que permiten precisar el ámbito de los derechos que la Constitución enumera y a la vez sirven para dar el calificativo de derecho humano o derecho fundamental a "otros" que ella omite lo mismo que a las garantías procesales de esos derechos que ella no consagra.

Aparte de la enunciación general del derecho de libre acceso a la justicia, contenida en el artículo 14.1 del Pacto Internacional de Derechos Civiles y Políticos, antes transcrito, merece particular atención el texto del artículo 25 de la Convención Americana de Derechos Humanos, que dice así:

“25.1. Toda persona tiene derecho a un recurso sencillo y rápido o a cualquier otro recurso efectivo ante los jueces o tribunales competentes, que la ampare contra actos que violen sus derechos fundamentales reconocidos por la Constitución, aun cuando tal violación sea cometida por personas que actúen en ejercicio de sus funciones oficiales."

Ese texto consagra el derecho a un recurso "sencillo y rápido", distinto del derecho de libre acceso a la justicia, que fue tratado bajo el número anterior, que la ampare contra actos que lesionen sus derechos fundamentales, se trata de un medio singularmente reforzado, con la misión específica ya indicada, que ampara a la persona contra los actos que violen los derechos individuales reconocidos por la Constitución. Ese derecho que especifica la Convención Americana puede individualizarse como amparo constitucional. 
4. El amparo como derecho a un medio judicial de protección. En derecho comparado los sistemas de protección jurisdiccional de los derechos inherentes a la persona humana y los medios procesales que los garantizan, suelen agruparse bajo una de estas dos soluciones. En uno, comúnmente llamado difuso, los tribunales ordinarios, incidenter tantum, estatuyen sobre el acto ilegítimo en el curso del proceso de que se encuentre apoderado. En el otro, que suele calificarse sistema concentrado, la transgresión es sometida a un organismo constitucionalmente instituido, dotado de atribuciones jurisdiccionales, al que se le atribuye competencia para decidir sobre la nulidad del acto ilegítimo mediante una decisión que es oponible erga omnes.

La vigencia de uno u otro sistema se fundamenta en hechos históricos y en concepciones políticas distintas que dan lugar a su implantación, tanto en lo que se refiere a la técnica jurídica que lo organiza como a los presupuestos ideológicos en que se fundamenta.

En países regidos por el sistema difuso de protección, como es la República Dominicana, ha sido frecuente la claudicación de la jurisdicción ordinaria a los regímenes políticos caracterizados por ser sistemáticos violadores de los derechos y de las libertades públicas, así como también, a ceder a las presiones y a otros medios de corrupción de parte de estructuras segmentarias de poder.

5. La persona beneficiaria de los derechos y garantías fundamentales que la Constitución reconoce por estar enumerados en su texto o, que sin estarlo, son de igual naturaleza, carece por sí sola de la fuerza necesaria que le permita sostenerlos. Para conjurar esa debilidad congénita, se reconoce a toda persona el libre acceso a la justicia para su protección contra las violaciones a sus derechos fundamentales, es lo que se denomina el derecho de amparo judicial ${ }^{4}$, que, en el sistema difuso de protección que nos rige, implica el recurso a cualquiera de las vías de procedimiento que pueden ser ejercidas, conforme a la ley, por ante las jurisdicciones ordinarias. En reconocimiento de la necesidad de su protección, el artículo 25.1 de la Convención Americana de Derechos Humanos consagra el derecho a otro medio procesal específico de protección, el amparo constitucional ${ }^{5}$. Por la dualidad de las fuentes que le dan nacimiento, el derecho de amparo no se identifica a una acción específica ni a ningún recurso determinado, por lo que no es ninguna vía procesal ni un medio judicial concreto, y puede con- 
figurarse tanto por el ejercicio de uno cualquiera de los procedimientos por los que comúnmente se apoderan las jurisdicciones judiciales o administrativas, o por su puesta en obra mediante un recurso o una acción autónoma susceptible de ser introducida bajo las características de sencillez y rapidez que perfila el citado artículo 25.1 de la Convención Americana.

En síntesis, el derecho de amparo como medio procesal para la protección de los derechos fundamentales frente a lesiones causadas por los representantes o agentes de los poderes públicos o por particulares es, en síntesis, el derecho de que disfruta cualquier individuo para reclamar la intervención efectiva de los tribunales del orden judicial o del orden administrativo a fin de ser amparados en el disfrute y ejercicio de los derechos y garantías que le son reconocidos constitucionalmente por cualquiera de las vías ordinarias de procedimiento, que es el amparo judicial, o por medio del recurso sencillo y rápido previsto en el artículo 25.1 de la Convención Americana de los Derechos Humanos, que es el amparo constitucional. En ambas hipótesis se desdobla en el deber de los tribunales apoderados de otorgar la protección que le es reclamada.

6. Es útil observar que en derecho mexicano el «juicio de amparo" abarca cinco acciones o recursos judiciales netamente diferenciados en el Derecho dominicano. Se distinguen, primero, el "amparo de la libertad", es el recurso de hábeas corpus; segundo, el "amparo contra la ley", que tiende a la declaratoria de la inconstitucionalidad de una ley, ya sea por la vía popular, que no tenemos, como por vía incidental en el curso de un proceso en que se aplique la ley cuestionada; tercero, el "amparo de casación", que corresponde a nuestro recurso en casación; cuarto, el "amparo administrativo", que corresponde a los recursos en nulidad de los actos administrativos que se ventilan ante la jurisdicción contencioso-administrativa, y quinto, el "amparo agrario", que no tiene símil en Derecho dominicano.

Al no existir regla constitucional alguna o de la ley que especifique que el derecho de amparo sólo sea practicable como una acción específica, o como un recurso único o sólo bajo una acción autónoma desvinculada de las demás acciones y recursos previstos en las leyes que constituyen los medios ordinarios del ejercicio del derecho de defensa, es valedero afirmar, por la ausencia de tales limitaciones, que en el pleno ejercicio del derecho de amparo coexisten la facultad de recurrir a las vías ordinarias ante los tribunales del orden judicial y del or- 
den administrativo (amparo judicial), y una acción de amparo, autónoma (amparo constitucional), cuya fundamentación será precisada más adelante $^{6}$.

Así, es concebible el ejercicio del derecho de amparo judicial, mediante la introducción de una acción o recurso ante un juez por el que se demanda la cesación o revocación de los hechos que lesionan o amenazan lesionar un derecho fundamental del demandante; mediante el ejercicio del recurso de hábeas corpus de acuerdo a la ley que lo reglamenta; por una demanda en nulidad de un acto administrativo ilegal, o en cesación de una vía de hecho ante la jurisdicción contencioso-administrativa, o simplemente por vía de excepción en el curso de un proceso de cualquier naturaleza. También es posible el ejercicio de la acción a que da lugar el derecho de amparo constitucional a que me refiero a seguidas.

7. La acción constitucional de amparo. Los medios procesales ordinarios del amparo judicial que acaban de ser glosados podrían, en determinados casos, no ofrecer las garantías de celeridad para ser calificados como suficientes, por lo que se plantea en derecho si es concebible la existencia de una acción de amparo independiente de esas vias ordinarias.

La doctrina, en un esfuerzo por hacer más efectivas las garantías procesales a los derechos fundamentales de la persona, sostuvo que el procedimiento de hábeas corpus es la vía común para la defensa de tales derechos ${ }^{7}$, con lo que se le daba las características de un derecho de amparo específicamente instituido. Diferido ese criterio en una contención judicial, fue rechazado por los tribunales. En efecto, la Suprema Corte de Justicia expresó: «En el estado actual de nuestro Derecho, los casos de prisión arbitraria o ilegal por obra de autoridades nacionales o de personas que usurpen autoridad, son los únicos que pueden dar lugar, válidamente, a un recurso por vía principal a los tribunales mediante el proceso de hábeas corpus;... en cuanto esos medios tratan de hacer reconocer a la institución de hábeas corpus un alcance que excede de su objeto específico y determinado, y de extenderla a la protección de la libertad de tránsito y de otros derechos humanos cuya protección, por los tribunales, no es tan directa como el caso de la seguridad individual, $y$ requiere otros cauces que, eventualmente, puedan llevar a la necesidad de una interpretación judicial, pero nunca por vía principal»" ${ }^{8}$.

\section{infra, n.o 7 .}

Del Castillo, Pellerano y Herrera, Derecho Procesal Penal, t. 2, p. 177.

Suprema Corte de Justicia, 17 de agosto de 1973, B. J. 753, p. 2.390. 
En la Argentina, en un estado del derecho igual al de República Dominicana, esto es, estando vigente una ley de hábeas corpus y sin reglamentación alguna que regulara o siquiera reconociera el derecho de amparo, la jurisprudencia de su más Alto Tribunal, al igual que la Suprema Corte dominicana, sentó el criterio de que el recurso de hábeas corpus "tiene por objeto esencial la libertad personal o corporal, por lo que no podría hacerse extensivo a la protección de otros derechos, los cuales deben ejercitarse conforme a los procedimientos creados por las leyes de la materia" ${ }^{9}$.

Apoderados los tribunales argentinos bajo las formas del recurso de hábeas corpus de una acción tendente a la protección de otros derechos de la persona, la Corte Suprema de la Nación reconoció, mediante su sentencia $20.344^{10}$, que en el caso juzgado no se trataba de un recurso de hábeas corpus, sino de un recurso directo de solicitud de amparo, que es el que corresponde para los otros derechos distintos a la seguridad individual. Los fundamentos de esa decisión son resumidos por CARLOS A. TAGLE " en los términos siguientes:

"Empieza la Corte desechando la alegación de que se haya utilizado la vía del recurso de hábeas corpus, afirmando además que no es éste el único medio expeditivo y adecuado para proteger los demás derechos de la persona. Fuera del hábeas corpus que se deriva implícitamente de la cláusula del art. 18, Const. Nac., "nadie puede ser arrestado sino en virtud de orden escrita de autoridad competente", y que ha sido reglamentado por leyes conocidas y por los códigos procesales, están los recursos directos de solicitud de amparo de los demás derechos (trabajar, publicar ideas por la prensa, disponer de la propiedad, ejercer su industria, asociarse, etc.) Y ellos, dice la mayoría, extráense de la "sabia norma del art. 33 de la Constitución", como lo hizo en el caso Siri y lo hace en el actual.»

"La invocación del art. 33 no puede ser más pertinente; si la libertad corporal de las personas ha de salvaguardarse prontamente, conforme a su garantía emanada de la cláusula pretranscrita del art. 18 , no puede argüirse que los demás derechos carezcan de garantías, ya que, si no la tienen expresa, la tienen implícita del art. 33, según el cual "las notas, declaraciones, derechos y garantías que enumera la Constitución no serán entendidos como negación de otros derechos y garantías no enumerados, pero que nacen del principio de la Soberanía del Pueblo y de la forma republicana de gobierno"."

9 Corte Suprema de la Nación Argentina, fallos 216 y 1.606, Jurisprudencia Argentina, 1950-111, p. 486, entre otras.

10 Jurisprudencia Argentina, 1958-IV, p. 216

$"$ Opus y loc. cit. 
La solución dada por la Corte Suprema de Argentina es totalmente valedera en la República Dominicana. En efecto, la doctrina de ambas Cortes concuerda. Ellas han sentado que la ley de hábeas corpus sólo se refiere a los casos en que se vulnere la seguridad personal mediante arrestos o detenciones ilegales por funcionarios o agentes de la autoridad pública o particulares.

Mientras que la argentina reconoce que la protección de los otros derechos fundamentales tiene lugar por un recurso admitido por los jueces del fondo y que ella calificó de amparo, la dominicana no resuelve cuáles son las vías propias que garantizan esos derechos, ella expresa que se "requieren otros cauces", lo que vale decir otros medios procesales distintos al hábeas corpus pero en modo alguno descarta el recurso de amparo admitido por los argentinos. Es necesario que se produzca un nuevo planteamiento ante los tribunales de una contención sobre un derecho fundamental distinto a la seguridad individual bajo la forma del ejercicio del derecho de amparo, a fin de que la jurisprudencia dominicana pueda decidir ese aspecto no juzgado.

Se debe observar que la decisión de la Suprema Corte de Justicia es del 17 de agosto de 1973 y que el derecho de amparo constitucional vino a ser reconocido posteriormente, cuando el 25 de noviembre de 1977, el Congreso Nacional aprobó la Convención Americana de Derechos Humanos, que prevé su existencia en su artículo 25.1.

En lo expresado se evidencia que en la dominicana el derecho de amparo tiene un doble fundamento: a) ser un medio de protección de los derechos de la persona distintos a su seguridad personal, y b) es una resultante del derecho de libre acceso a la justicia contra actos que violen sus derechos fundamentales, que es el amparo judicial y además está expresamente consagrado en la citada convención, que es norma de derecho interno dominicano con rango constitucional, al que llamo amparo constitucional.

8. El objeto del amparo. El derecho de amparo tiene por objeto asegurar a todo individuo el goce $y$ el ejercicio de los derechos y garantías constitucionales, lo que vale decir, de los que enumera la Constitución al igual que los no reproducidos en la última reforma pero que figuran en anteriores, de los que se enumeran en las convenciones internacionales y de los que en ellas se les da mayor amplitud a los que la la argentina.

12 El artículo 10 de la Constitución dominicana es el equivalente al 33 de 
Constitución especifica, e igualmente, tiene por objeto asegurar el ejercicio de los derechos y garantías contenidos en las leyes que regulan cualquiera de los derechos fundamentales.

Para la eficacia de ese goce y ejercicio es indispensable que el juez que habrá de estatuir sobre el amparo pueda disponer de las medidas cautelares necesarias para la suspensión inmediata de la violación cometida, al igual que disponer sobre el fondo de la cuestión planteada, de manera que resuelva definitivamente sobre la transgresión o la ilegitimidad de la perturbación al derecho o garantía constitucionalmente instituido.

9. Consecuencias del amparo como derecho fundamental. De los textos citados precedentemente y de cuanto ha sido expuesto resulta que del derecho de amparo en sus formas judicial y constitucional se derivan las consecuencias siguientes:

a) Se trata de un derecho fundamental de la persona ${ }^{13}$, no de una acción o recurso particular que se ventila ante un tribunal determinado. Rige en todos los mecanismos procesales establecidos en la ley que en cualquier forma permitan alcanzar su objetivo.

b) El ejercicio del derecho de amparo impone al tribunal apoderado la obligación de amparar al demandante contra los actos constitutivos de las violaciones a los derechos y garantías en que se basa el apoderamiento, ya sea cuando su materialización se hace a través de acciones o recursos establecidos en la ley (amparo judicial), al igual que cuando es apoderado por la acción autónoma de amparo (amparo constitucional), que es interpuesta mediante un recurso sencillo y rápido o judicialmente efectivo tendente a obtener el amparo de los derechos fundamentales y a la vez a restablecer de inmediato la situación jurídica violada.

c) Dicho en otras palabras, el derecho de amparo (judicial) puede ser ejercido mediante las acciones, recursos y excepciones establecidos en la ley, tales como: por el planteamiento de un medio de defensa, o por la excepción de inconstitucionalidad en el curso de un proceso en el que se plantea la lesión a un derecho fundamental, o mediante una acción principal ante un

13 Es lo consagrado por el artículo 49 de la Constitución de Venezuela. 
juez tendente a anular un acto ilícito que provenga de un funcionario o agente de los poderes públicos, ya sea por un recurso por exceso de poder o a consecuencia de su apoderamiento por vía principal de una excepción de ilegalidad del acto en cuestión o contra la ejecución de ese acto, o bien por una demanda contra el autor de un daño por la que se pretenda hacer cesar una vía de hecho. También el derecho de amparo puede ser ejercido por medio de la acción autónoma (amparo constitucional) cuyo fundamento ha sido indicado precedentemente ${ }^{14}$.

d) El derecho de amparo protege el goce y el ejercicio de los derechos fundamentales reconocidos por la Constitución, así como los demás derechos y garantías constitucionales, incluyendo los consagrados por las leyes reglamentarias de esos derechos y garantías, por lo que puede ser ejercido para hacer cesar las perturbaciones a los derechos individuales enumerados por la Constitución o reconocidos como tales en virtud del artículo 10, lo mismo que cuando existen lesiones a los derechos sociales, económicos y políticos de la persona.

La posibilidad de su ejercicio corresponde a todos, sin distingo alguno, comprendiéndose a las personas físicas y a las personas morales.

e) Una vez que el derecho de amparo tiende a proteger el goce y el ejercicio de los derechos y garantías constitucionales contra cualquier turbación, es indiferente quien la haya causado, ya sea cualquier autoridad pública o particular. En los casos de turbaciones causadas por funcionarios o agentes de los poderes públicos, el derecho de amparo procede contra los actos legislativos, los actos administrativos, los actos calificados vías de hecho de la administración y contra los actos judiciales mediante el ejercicio de los recursos y acciones previstos en la ley (excepción de inconstitucionalidad, vías de recurso, recurso contencioso-administrativo de anulación), siempre y cuando sean susceptibles de restablecer la situación jurídica violada.

f) Como el derecho de amparo busca asegurar el goce y ejercicio de todos los derechos fundamentales y las garantías de éstos, su ejercicio es admisible tanto cuando exista una violación di- 
recta de lo previsto en un texto constitucional o a uno de los principios que ella consagra, como a los otros derechos que se cobijan bajo las previsiones de su artículo 10, al igual que las normas legales que han sido dictadas por mandato de la propia Constitución, por ejemplo, las previsiones de la Ley número 5.353 del año 1914 y sus modificaciones, sobre hábeas corpus.

g) La sentencia que dicte el juez apoderado sobre el ejercicio del derecho de amparo debe disponer cuanto se refiera a la procedencia de medidas cautelares o preventivas, al igual que resolver lo concerniente al fondo de la contestación, estatuyendo sobre la legalidad o no de la turbación denunciada o de la garantía constitucional violada.

\section{LA ADMISIBILIDAD DE LA ACCIÓN AUTÓNOMA DE AMPARO}

10. De acuerdo a lo expresado, el reconocimiento del derecho de amparo como la aptitud para ejercer un recurso sencillo y rápido ante los jueces y tribunales competentes que le ampare contra actos que violen sus derechos fundamentales, le da la categoría de derecho humano, tanto por ser una consecuencia del derecho más amplio de reclamar la protección de jueces y tribunales ante cualquier transgresión a sus derechos, como por serle reconocida esa calificación en el artículo 25.1 de la Convención Americana de Derechos Humanos, elevado a rango constitucional por el artículo 10 de la Constitución. Esa naturaleza obliga a reconocer que su ejercicio siempre debe ser efectivo, ya sea que se haga por las vías ordinarias de procedimiento (amparo judicial), o a través de la acción autónoma (amparo constitucional), que permita hacer efectivo el derecho en los casos en que resulten insuficientes o no fuere posible recurrir a él.

Sin embargo, la coexistencia de las diversas vías de los procedimientos ordinarios (amparo judicial) y la acción autónoma (amparo constitucional) abre la posibilidad a que el ejercicio concurrente de ambas variantes del derecho de amparo, provoque el desquiciamiento o el caos del sistema jurídico procesal, por lo que se debe reconocer la necesidad de que se agoten las vías ordinarias que pueden ser ejercidas por el amparo judicial antes de que se recurra a la acción autónoma del amparo constitucional, a menos que el recurso a ellas viniera a ser tan tardío que hiciera ineficaz el fin perseguido. Éste es el sistema de interpretación ve- 
nezolano, en un Estado del derecho similar al dominicano, en el que la Constitución reconoce el derecho de amparo sin que exista legislación adjetiva que reglamente el ejercicio de la acción correspondiente. En efecto, conforme al criterio emitido por su más alto tribunal: la Corte Suprema de Venezuela, en una sentencia del 20 de octubre de 1983, se afirma que "el Tribunal no puede entrar a decidir las acciones de amparo si existe un recurso o acción judicial paralelo e idóneo como medio de amparo, como en materia de actos administrativos son los recursos contencioso-administrativos de anulación" ${ }^{15}$, sistema de interpretación que ya había sido ratificado por la Corte Primera de lo Contencioso Administrativo venezolana en sentencia del 25 de enero de 1984, en la que, al referirse al recurso de amparo expresa que "esta acción es un medio extraordinario (sic) de protección que sólo puede ser utilizado cuando no existan vías a través de las cuales puedan obtener el restablecimiento de los derechos subjetivos" ${ }^{16}$.

11. El amparo frente a las actuaciones de los particulares. Siendo el derecho de amparo la vocación al ejercicio de múltiples acciones y recursos tendentes a proteger un derecho constitucionalmente garantizado, es necesario reconocer que el mismo protege las lesiones o menoscabos a los derechos y garantías constitucionales causadas por los funcionarios o agentes de la autoridad pública al igual que laș transgresiones cometidas por particulares. Esta es la solución que da la ley número 5.353 al recurso de hábeas corpus, que es una variedad del derecho de amparo.

\section{LOS PRINCIPIOS QUE RIGEN LA ACCIÓN AUTÓNOMA DE AMPARO}

12. Como resultado de los textos y principios invocados, la acción autónoma de amparo (amparo constitucional) puede ser ejercida ante todos los tribunales, de conformidad con las normas propias de su competencia, como un remedio procesal efectivo para proteger y asegurar todos y cada uno de los derechos inherentes a la persona humana y las garantías que reconoce la Constitución o son la consecuencia de tales derechos, frente a cualquier turbación causadas por actuaciones de la autoridad pública o de simples particulares, mediante el agotamiento de un

15 Citada por Brewer Carías, A., Estado de Derecho y Control Judicial, p. 616.

${ }_{16}$ Citada por Brewer Carias, A., op. cit., p. 617. 
procedimiento sencillo y rápido que culmine con una decisión del juez apoderado que restablezca la situación jurídica vulnerada.

13. La ausencia de una ley que regule el derecho de amparo no impide el ejercicio de la acción autónoma. Cuando la Suprema Corte de Justicia expresó en su sentencia del 17 de agosto de 1973, precitada, que "en cuanto esos medios tratan de hacer reconocer a la institución de hábeas corpus un alcance que excede de su objeto específico y determinado, y de extenderla a la protección de la libertad de tránsito y de otros derechos humanos cuya protección... requiere otros cauces..." ${ }^{17}$, negó la posibilidad de que la institución de hábeas corpus sea extendida a la salvaguarda de otros derechos humanos y a la vez reconoció que la protección de esos otros derechos "requiere otros cauces", lo que implica una referencia expresa a otras acciones y recursos que no fueron identificados en la sentencia.

El artículo 25.1 de la Convención Americana de Derechos Humanos, adoptada por los poderes públicos con posterioridad a esa sentencia del más alto tribunal, no consagra una acción única de amparo, una vez que permite reclamar la vigencia de ese derecho a través de un recurso sencillo y rápido, que es la acción autónoma a que me refiero, o mediante cualquier otro procedimiento "efectivo", el cual únicamente puede ser alguno de los medios procesales ordinarios, si mediante él se puede alcanzar la efectividad que se requiere en ese texto.

El hecho de que no exista una ley que reglamente la forma de proceder en el ejercicio de la acción autónoma de amparo no menoscaba el ejercicio de ese derecho, puesto que de no ser así sería ilusorio su reconocimiento como derecho humano, con lo que se decapitaría totalmente la norma establecida por el artículo 10 de la Constitución y a la vez se convertirían esos derechos y sus garantías en «meras declaraciones retóricas sin contenido real ${ }^{18}$. La doctrina de la sentencia de la Corte Suprema de Argentina antes mencionada confirma esta solución.

14. La competencia para conocer de la acción de amparo. De lo dispuesto por la Suprema Corte de Justicia en su sentencia del día 17 de agosto de 1973, antes citada, resulta que el procedimiento de hábeas corpus es privativo para las violaciones a la seguridad personal conforme a la ley número 5.353, del año 1914, y sus modificaciones, y a la vez ina-

17 B. J. 753, P. 2390.

18 Sentencia de la Suprema Corte de Justicia de Venezuela en Sala Política Administrativa del 20 de octubre de 1983, citado por BrEWER CARís, A., op. cit., p. 624. 
plicable a las otras acciones relativas a la protección de los demás derechos y garantías constitucionales. Es razonable que sea así, puesto que la aplicación de las normas de procedimiento y de competencia previstos en esa ley a asuntos de naturaleza distinta a los casos penales podría provocar gran confusión en la distribución de las competencias judiciales.

Como el derecho de amparo puede ser ejercido conforme a las normas de los distintos procedimientos ordinarios con los que sea posible alcanzar el objeto perseguido (amparo judicial), los tribunales, penales, civiles, comerciales o laborales, y los del orden administrativo, deben reconocer su aptitud para entender de los "recursos de amparo de acuerdo con la afinidad que con su competencia natural tengan los derechos que se pretendan vulnerados", usando aquí el criterio que al respecto mantiene la Corte Suprema de Justicia de Venezuela en sentencia dictada en Sala Político-Administrativa el 20 de octubre de $1983^{19}$. Esa Corte ha admitido que el amparo podría resultar de la nulidad manifiesta de un acto administrativo, para reconocer la competencia de la jurisdicción contencioso-administrativa, así como establecer que una acción de amparo podría resultar de actos violatorios del derecho de trabajo cometidos por empresas, para deducir que por la afinidad de la competencia debe ser introducida ante la jurisdicción laboral ${ }^{20}$.

15. Carácter subsidiario del amparo constitucional. El carácter subsidiario de la acción autónoma de amparo resulta de la fórmula del artículo 25.1 de la Convención Americana de los Derechos Humanos, que la consagra, una vez que reconoce el ejercicio del derecho de amparo mediante "un recurso sencillo y rápido", o mediante "cualquier otro recurso efectivo". Esas expresiones de la Convención Internacional admiten la posibilidad de que el amparo pueda ser accionado por una acción autónoma, que es la primera de sus hipótesis, que he llamado amparo cons: titucional, o por cualquier otro recurso efectivo, que es la segunda, y son los medios procesales ordinarios por los que pueda alcanzarse esa efectividad en la solución de la violación cometida (amparo judicial).

Aun cuando pudiera sostenerse que ese texto abre la posibilidad al ejercicio conjunto de las acciones, la conveniencia de mantener soluciones armónicas con la organización judicial y con la administrativa aconsejan a reconocer una acción de amparo principal a través de los procedimientos ordinarios (amparo judicial) y otra acción de amparo subsidiaria (amparo constitucional), ésta última mediante el empleo anté

19 Citada por Brewer Carías, A., op. cit., p. 627.

20. Citada por Brewer Carías, A., op. y loc. cit. 
cualquier juez o tribunal competente de un procedimiento sencillo y rápido, que sólo podría ser puesto en obra cuando no exista otra vía judicial o administrativa que satisfaga su objetivo, $o$, dicho en otras palabras, y aquí invoco la autoridad de la Corte Primera de lo Contencioso-Administrativo de Venezuela, en sentencia dictada el 20 de enero de 1986, en la que expresa: "El carácter excepcional y residual del amparo como acción judicial especial sólo se atenúa en los casos en los cuales existe la imposibilidad de obtener la satisfacción del derecho lesionado por las vias normales que el orden jurídico establece... que si bien el amparo tiene naturaleza extraordinaria, sin embargo, ante la circunstancia específica que obliga a la protección inmediata del derecho lesionado cuyo daño se transformaría en irreparable si no se le otorgase en la forma la tutela se admite su procedencia" ${ }^{21}$, precisando esa Corte su doctrina en esa misma sentencia, "que por el fin que persigue la Constitución... de la inmediata protección de las garantías constitucionales, y en concreto de lograr el restablecimiento oportuno de las situaciones jurídicas infringidas, cuando los medios ordinarios que existen en contra de los actos inconstitucionales o ilegales, sean insuficientes para reparar el perjuicio, o no idóneos para evitar el daño o la lesión causada, por tales actos, la acción autónoma de amparo, entonces resulta procedente. $Y$ si a esta inidoneidad o insuficiencia se agrega la incertidumbre en que se coloca al interesado respecto al ejercicio de un derecho, por la no operatividad inmediata del recurso ordinario o normal contra el acto ilegal, está plenamente justificado el amparo como pretensión procesal autónoma, que busca precisamente la protección judicial para que se evite un daño existente, o se impida uno ciertamente inminente o irreparablen ${ }^{22}$.

16. El carácter sencillo y rápido del procedimiento. El artículo 25.1 de la Convención Americana de Derechos Humanos reconoce a toda persona el derecho a "un recurso sencillo y rápido", ante los jueces o tribunales que la ampare contra los actos que violen sus derechos fundamentales. Las formas simples del procedimiento sumario satisfacen el requisito de la sencillez y la noción de urgencia en el derecho procesal suple los elementos necesarios para satisfacer la rapidez requerida. Ese artículo también prevé otra hipótesis, la existencia de cualquier otro recurso efectivo que le permita alcanzar los mismos fines.

Como la acción autónoma de amparo puede ser ejercida ente cualquier jurisdicción "de acuerdo con la afinidad que su competencia natural tengan los derechos que se pretendan vulnerados ${ }^{23}$, se debe de-

27 Citada por Brewer Carías, A., op. cit., p. 632.

22 Citada por Brewer Carías, A., op. cit., p. 633.

23 Supra, n. 13. 
terminar cuál es el tribunal a ser apoderado y el procedimiento a ser empleado, de acuerdo a su competencia natural. Así, siempre será posible recurrir a las formas simples y rápidas del referimiento, una vez que rige para todas las materias, tal como lo dispone el artículo 111 de la Ley 834 del año 1978. Las formas sencillas del procedimiento de hábeas corpus pueden ser empleadas en los casos en que proceda el apoderamiento de un juez de lo penal.

17. Los poderes del juez del amparo. Al establecer el artículo 25 de la Convención Americana de Derechos Humanos que el recurso ante los jueces y tribunales competentes amparará contra los actos de violencia los derechos fundamentales y que la autoridad competente decidirá sobre los derechos de toda persona que interponga el recurso, resulta que el juez dispone de los más amplios poderes para ordenar medidas precautorias y disponer lo que estime procedente para hacer efectivo al amparo de los derechos fundamentales. Igualmente puede dictar órdenes o imponer prohibiciones a quien ha violado el derecho y a la vez disponer el restablecimiento de la situación jurídica infringida, cuando fuere posible. 